\title{
Review
}

\section{Brain Natriuretic Peptide in Hypertension}

\author{
Tadanao Takeda, and Masakazu Kohno
}

\begin{abstract}
Brain natriuretic peptide (BNP) was first identified in the porcine brain and later isolated from porcine, rat, and human hearts. In humans, plasma BNP concentrations are progressively elevated with increasing severity of hypertension, particularly when left ventricular hypertrophy (LVH) is present. This presumably reflects increases in ventricular mass associated with increased synthesis and constitutive secretion of BNP from ventricular tissue. In this respect, plasma BNP may be a marker for hypertensive LVH. Acute administration of BNP induces significant natriuresis and suppresses plasma aldosterone in hypertensive subjects. However, further studies are necessary to clarify the pathophysiological significance of BNP in essential hypertension. (Hypertens Res 1995; 18: 259-266)
\end{abstract}

Key Words: brain natriuretic peptide, hypertension

The role of the heart as an endocrine organ was conclusively demonstrated by de Bold et al. in 1981 (1), and the identification of atrial natriuretic peptide (ANP), the first member of the natriuretic peptide family, was demonstrated by Kangawa and Matsuo in 1984 (2). The second member of this family, brain natriuretic peptide (BNP), was first identified in the porcine brain and later isolated from the porcine heart (3). Porcine BNP consists of 26 amino acid residues that share considerable homology with the sequence of ANP. BNP elicits a spectrum of diuretic, natriuretic, and hypotensive effects, similar to those induced by ANP. Subsequently, a low-molecular-weight form of human $\mathrm{BNP}$, human BNP-32, which corresponds to the Cterminal sequence (77-108) of the human BNP precursor deduced from the cDNA sequence, was found in human atrium $(4,5)$ and human plasma (6).

This paper summarizes available data concerning the structure of BNP and the release mechanism of this peptide. Secondly, studies documenting the biological effects of BNP under physiological and pathophysiological conditions are reviewed. Thirdly, studies documenting plasma concentrations of this peptide and its physiological role in hypertension are reviewed. Finally, the possibility of BNP as a novel form of therapy for hypertension is discussed.

\section{Structure}

In normal man the major circulating form of BNP consists of 32 amino acids (human BNP-32) with a characteristic ring structure, formed by an intramolecular disulfide bridge, and amino- and carboxyl-terminal tails (5) (Fig. 1). The central structure is similar to both ANP and the recently described C-type natriuretic peptide (CNP), but the terminals vary considerably in length and amino acid composition (7). Human BNP-32 is also the major circulating form of BNP in hypertensive patients (8) (Fig. 2).

A single copy gene encodes human BNP and, similarly to the ANP gene, it consists of three exons and two introns. A characteristic feature that distinguishes between the messenger RNA of the peptides is a highly conserved sequence in the 3' untranslated region of the BNP form consisting of four sets of AUUUA $(9,10)$, which is considered to produce messenger RNA instability (11). This finding suggests that at the transcriptional level the BNP gene expression is regulated in a different manner from that of ANP.

\section{Secretion}

ANP and BNP are cosecreted through the coronary sinus from human heart $(4,8)$ (Fig. 3 ), but ANP is secreted mainly from the atria and BNP from the cardiac ventricles. For instance, plasma levels of both BNP and ANP increase during dynamic exercise and are correlated with each other in hypertensive subjects (12). The increase of both peptides is inhibited by the administration of angiotensin-converting enzyme inhibitor (ACEI) (Fig. 4). Supraventricular tachycardias provoke transient elevations of both plasma BNP and ANP (13). Like ANP, several studies have demonstrated positive correlations between BNP release and the left ventricular end-diastolic pressure (14), pulmonary artery wedge pressure, and pulmonary artery pressure (15) in normal subjects, hypertensive subjects,

From the First Department of Internal Medicine, Osaka City University Medical School, 1-5-7 Asahi-machi, Abeno-ku, Osaka 545, Japan.

Address for Reprints: Tadanao Takeda, M.D., First Department of Internal Medicine, Osaka City University Medical School, 1-5-7 Asahi-machi, Abeno-ku, Osaka 545, Japan.

Received June 27, 1995. 


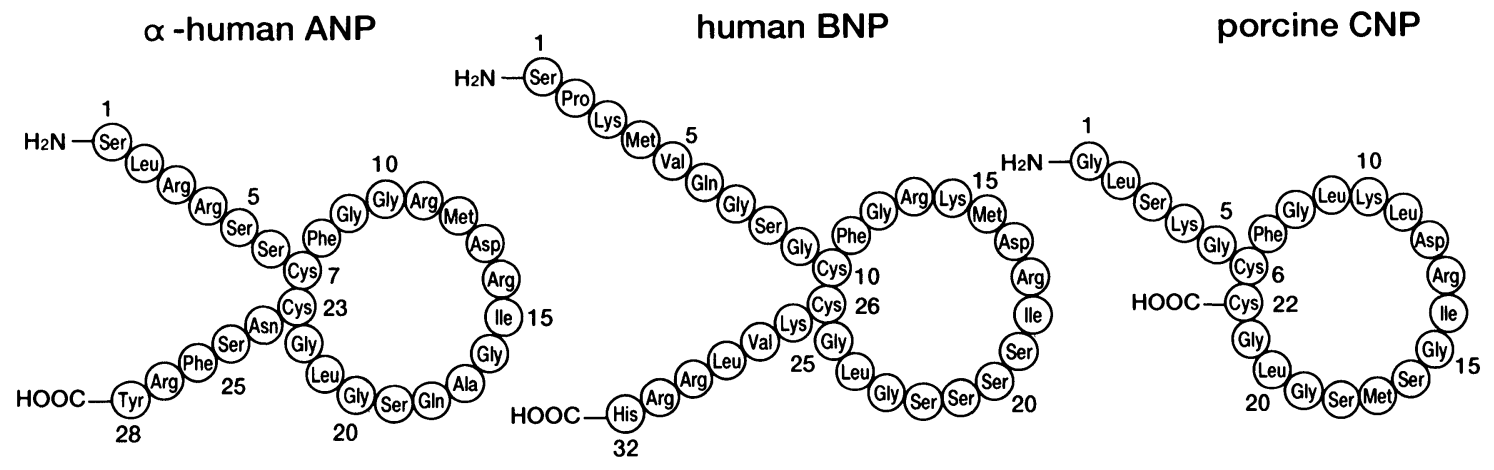

Fig. 1. Structure of atrial natriuretic peptide, brain natriuretic peptide, and C-type natriuretic peptide.

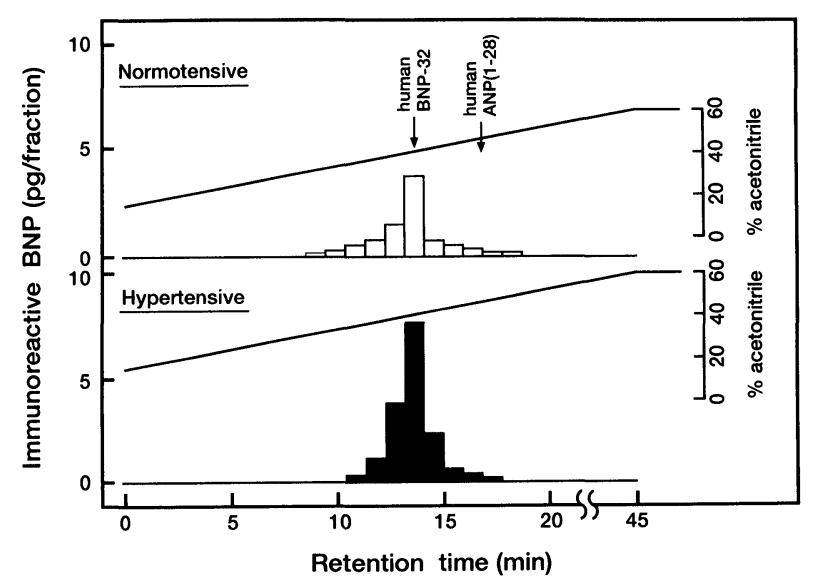

Fig. 2. Profiles by reverse-phase high performance liquid chromatography of immunoreactive BNP in extracts of pooled plasma from hypertensive subjects and normotensive subjects. The elution positions of standard human $B N P-32$ and human ANP (1-28) are shown by the arrows.

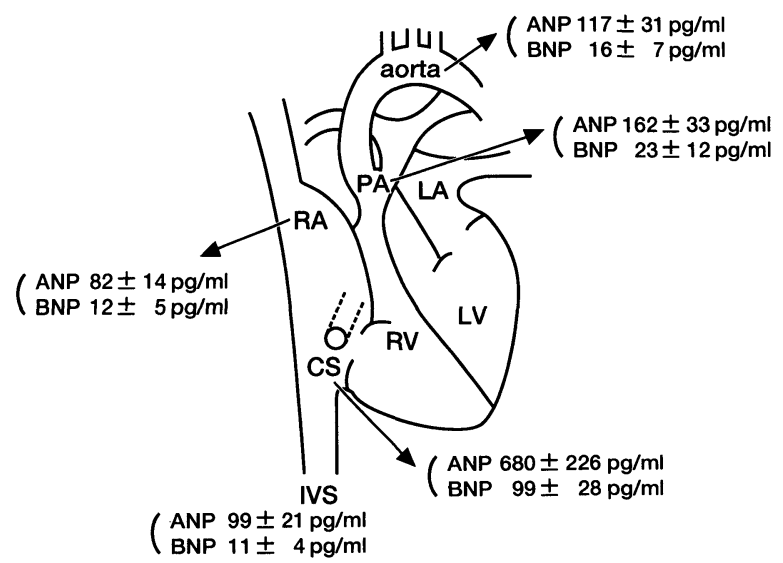

Fig. 3. Intracardiac sites of $A N P$ and BNP concentrations in patients undergoing cardiac catheterization.

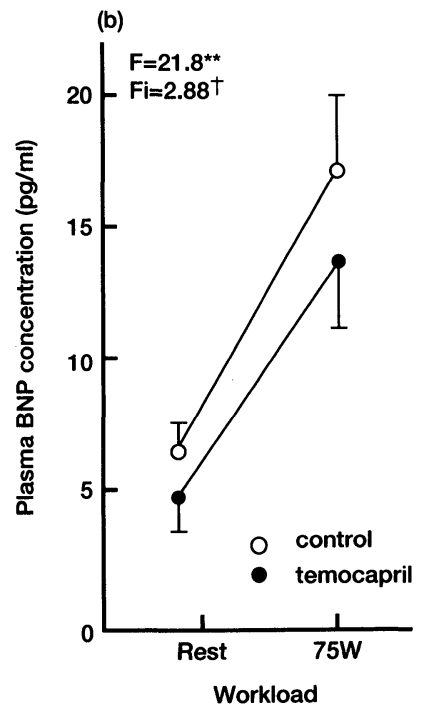

Fig. 4. Plasma ANP and BNP increase during dynamic exercise and are correlated with each other in hypertensive subjects. Plasma ANP (a) and plasma BNP (b) levels at rest and at a $75 \mathrm{~W}$ workload before $(\bigcirc)$ and during (O) treatment. Statistical analysis was done by three-way analysis of variance. F, the effect of treatment; Fi, the interaction between treatment and the level of activity. ${ }^{* *} \mathrm{p}<0.01 ;{ }^{* * *} \mathrm{p}<0.001 ;$ Statistically not significant. 
Table 1. Biological Actions of Brain Natriuretic Peptide

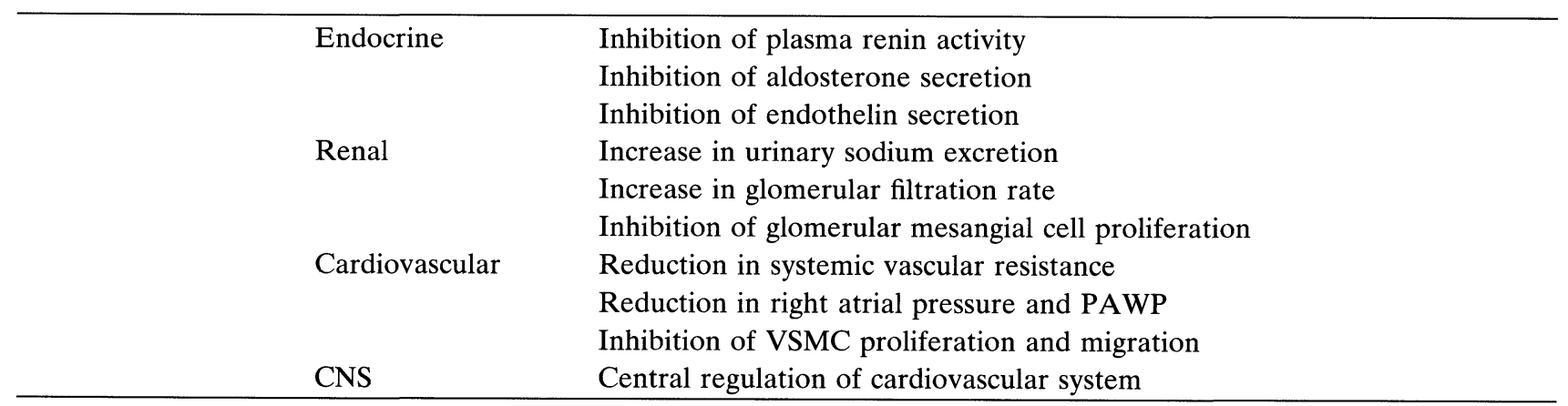

VSMC, vascular smooth muscle cell; PAWP, pulmonary artery wedge pressure; CNS, central nervous system.

and patients with congestive heart failure. Actually, an immunocytochemical study using antisera highly specific for ANP and BNP indicates the coexistense of ANP and BNP in the secretory granules of human cardiac myocytes (16).

However, there is some evidence that the response of BNP release to various stimuli differs from that of ANP. Richards et al. (17) have demonstrated that the change from upright to supine posture stimulates ANP release, but has no effect on the plasma BNP concentration. They have also demonstrated that pressor infusions of angiotensin II increase plasma levels of both peptides, but the increment in BNP is much less than that in ANP. Horio et al. (18) have examined the serial changes in ANP and BNP in patients with acute myocardial infarction treated with early coronary angioplasty. Plasma levels of both peptides are increased on the first day of the infarction. During the clinical course of the infarction, ANP levels soon decrease, while BNP levels remain elevated 2 weeks after the infarction and also exhibit a high level at 4 weeks. Therefore, it is likely that the regulation of plasma $\mathrm{BNP}$ and its response to various stimuli is different from that of ANP. Actually, there is evidence to suggest that the secretion of BNP is augmented by the activation of protein kinase $C$, but that, unlike ANP, it does not depend on the free intracellular calcium concentration (19).

\section{Biological Effects of BNP}

The natriuretic effects of BNP have been clearly demonstrated in animal and human studies using pharmacological doses (20-22). Although the exact cellular mechanism is not clear, BNP increases urinary sodium excretion. BNP binds to receptors in cultured inner medullary collecting duct cells and inhibits sodium uptake by these cells (23). There is also indirect evidence for the inhibition of sodium transport in the proximal tubule (24). BNP also may increase urinary sodium excretion by alteration of the glomerular filtration rate. However, this process may not be necessary for the increase in urinary sodium excretion, because infusions of BNP sufficient to cause natriuresis do not alter the glomerular filtration rate $(25)$.
Biological actions of BNP under physiological and pathophysiological conditions are summarized in Table 1. Various kinds of endocrine effects have been demonstrated. It is a potent inhibitor of aldosterone secretion like ANP $(26,27)$. BNP also inhibits plasma renin activity in dogs (28). In humans, a decline $(21)$ or no significant change $(29,30)$ in plasma renin activity during the infusion of BNP has been reported.

Interaction between BNP and endothelin has been shown. In cultured vascular endothelial cells, endothelin-1 is stimulated by angiotensin II and thrombin, and this can be potently inhibited by BNP as well as ANP $(31,32)$. Taken together with endothelin stimulation of BNP and ANP secreted from the heart (33-36), these findings suggest the existence of a cardiac-endothelium feedback mechanism (Fig. 5). In glomerular mesangial cells, BNP also inhibits endothelin-1 production induced by angiotensin II (37), arginine vasopressin (38), and platelet-derived growth factor (39).

The hemodynamic effects of BNP have been demonstrated in various species. Pharmacological doses of BNP cause a profound and sustained fall in blood pressure in hypertensive rats (22). However, in hypertensive subjects blood pressure was not significantly changed during infusions of BNP (25). In patients with congestive heart failure, a significant fall in pulmonary artery wedge pressure, right atrial pressure, and systemic vascular resistance associated with a rise in the cardiac index was observed (30).

Central regulation of the cardiovascular system may be also affected by BNP. In rats the injection of BNP into sites in the ventrolateral medulla causes a reduction in heart rate and blood pressure (40). In addition, the intracerebroventricular injection of BNP attenuates the stimulatory effect of endothelin-1 on arginine vasopressin release (41).

\section{Plasma BNP in Hypertension}

The plasma BNP concentration is modestly elevated in many patients with untreated essential hypertension as compared with normotensive controls, although the values in normotensive and hypertensive subjects overlap $(8,42)$. BNP concentration is also modestly elevated in patients with secondary 


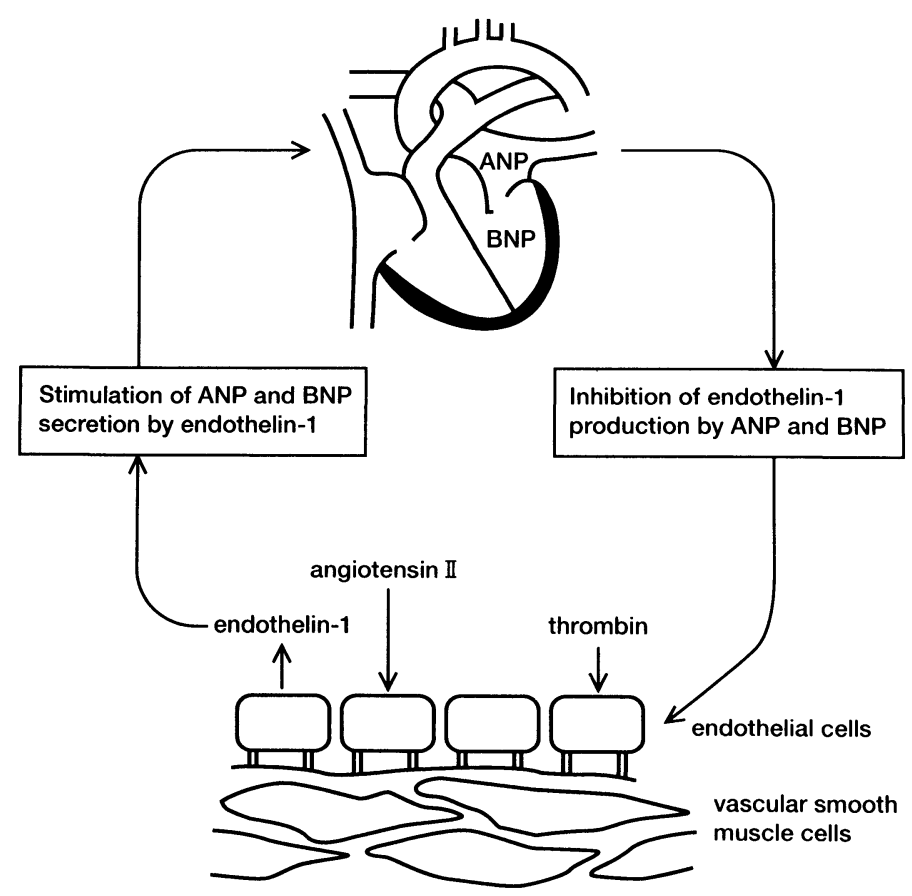

Fig. 5. Possible existence of a cardiac-endothelium feedback loop.

hypertension associated with diseases such as primary aldosteronism and Cushing syndrome (42). Hypertensive patients with left ventricular hypertrophy (LVH) have higher plasma BNP concentrations than those without LVH and much higher BNP concentrations than normotensive controls. Interestingly, there is a close, positive correlation between BNP levels and echocardiographic left ventricular mass index (8) (Fig. 6).

A heart perfusion experiment performed by Langendorff's method before and after atrial removal in normotensive rats indicates that about $55 \%$ of all BNP is secreted from the ventricle. In contrast, about $95 \%$ of ANP is secreted from the atria (43). On the other hand, a heart perfusion study before and after atrial removal in experimental hypertension with severe LVH in rats suggests that most BNP $(70 \%)$ is secreted from the hypertrophied ventricles (43) (Table 2). These findings suggest the hypothesis that in hypertensive subjects with $\mathrm{LVH}$, a considerable amount of BNP is secreted from the hypertrophied left ventricle and, therefore, the major origin of circulating BNP in these patients may be the hypertrophied ventricles. Hence, plasma BNP concentrations are increased in hypertension, and this is most pronounced when $\mathrm{LVH}$ is present. Previously, Mukoyama et al. have demonstrated that plasma BNP concentration is high in congestive heart failure and often surpasses the concentration of ANP (42). Plasma BNP concentrations in patients with severe heart failure (NYHA class III or IV) are much higher than those in patients with less severe failure (NYHA class I or II). It is therefore likely that plasma BNP concentrations better reflect left ventricular mass and load.

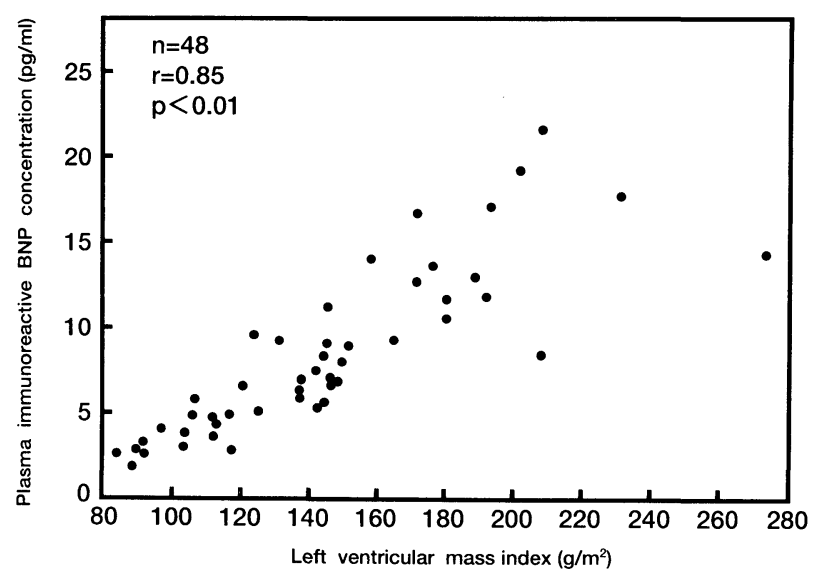

Fig. 6. Relationship of plasma BNP concentration to left ventricular mass index in the hypertensive subjects.

Recently, we (44) have demonstrated that longterm therapy with ACEI can reduce elevated concentrations of ANP and BNP in hypertensive patients (Fig. 7), and that the reduction in BNP is closely related to diminishing LV mass (Fig. 8). In contrast, there is no significant relationship between reductions in BNP and mean blood pressure. Thus, changes in plasma BNP appear to reflect the magnitude of regression of $\mathrm{LVH}$ rather than changes in blood pressure level during antihypertensive treatment.

In hypertensive rats with severe LVH, we (45) have shown that the reduction in ventricular mass by chronic ACEI therapy and angiotensin-II receptor antagonism reduces the BNP secretory rate from 
Table 2. Concentrations of Atrial and Brain Natriuretic Peptides in the Perfusate from Isolated Hearts before and after Atrial Removal in Wistar-Kyoto Rats and Spontaneously Hypertensive Rats with Deoxycorticosterone-Acetate and Salt

\begin{tabular}{lcc}
\hline \multicolumn{1}{c}{ Measurements } & WKY & DOCA-salt SHR \\
\hline Systolic BP (mmHg) & $133 \pm 6$ & $268 \pm 10^{*}$ \\
Ventricular/ body weight (mg/g) & $2.80 \pm 0.12$ & $4.81 \pm 0.59^{*}$ \\
ANP & & $4,260 \pm 420^{*}$ \\
Before atrial removal (pg/min) & $1,914 \pm 205$ & $352 \pm 60^{*}$ \\
After atrial removal (pg/min) & $109 \pm 15$ & $92 \pm 1^{*}$ \\
Secretory rate from atria (\%) & $94 \pm 1$ & $603 \pm 51^{*}$ \\
BNP & $207 \pm 16$ & $422 \pm 30^{*}$ \\
Before atrial removal (pg/min) & $118 \pm 15$ & $70 \pm 5^{*}$ \\
After atrial removal (pg/min) & $57 \pm 4$ & \\
Secretory rate from ventricles $(\%)$ & & \\
\hline
\end{tabular}

WKY, Wistar Kyoto rats; SHR, spontaneously hypertensive rats; DOCA, deoxycorticosterone acetate; BP, blood pressure; ANP, atrial natriuretic peptide; BNP, brain natriuretic peptide. ${ }^{*} p<0.05$ vs. WKY.
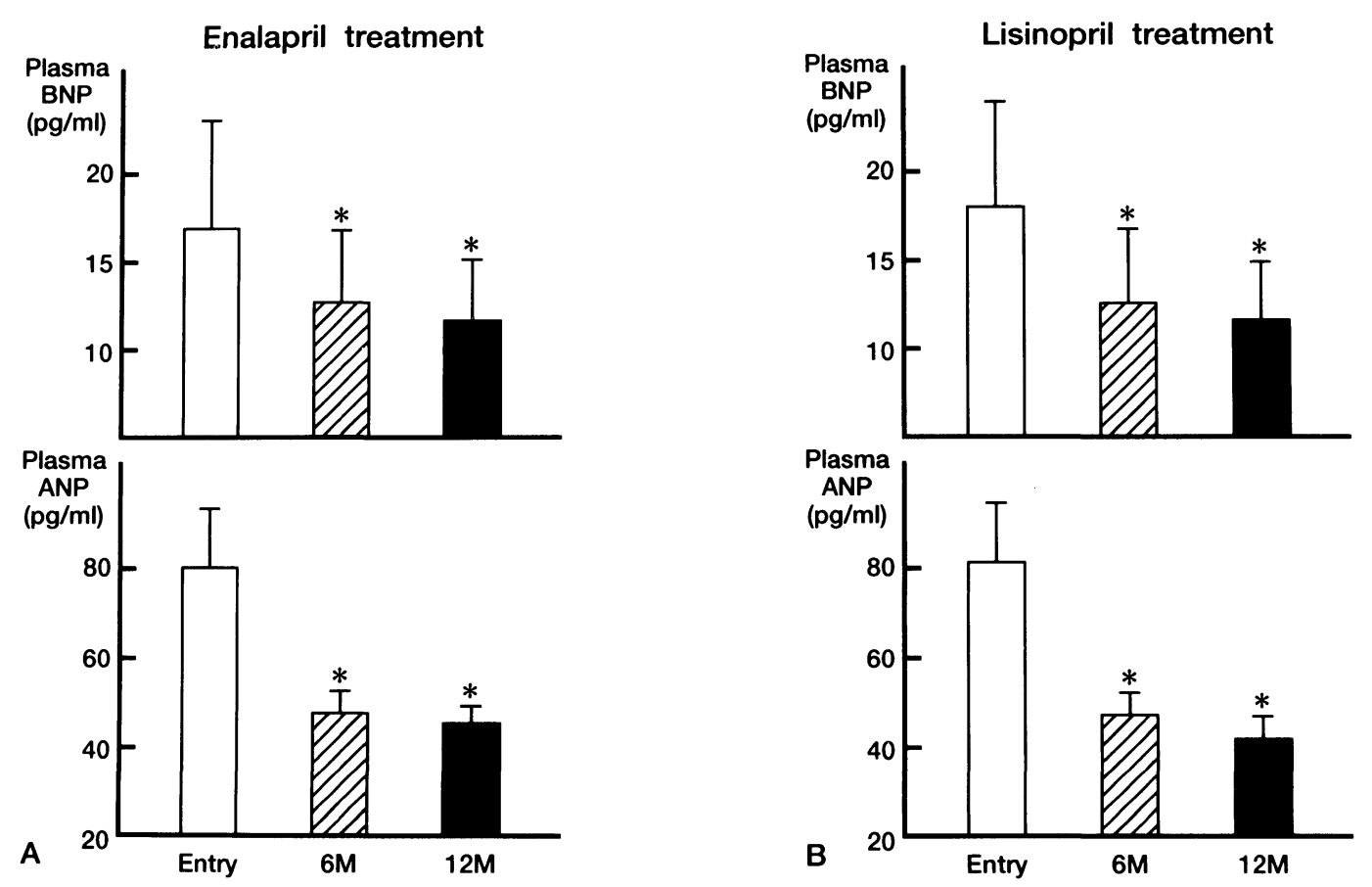

Fig. 7. A. Changes in plasma brain natriuretic peptide (BNP) concentration (upper panel) and plasma atrial natriuretic peptide $(A N P)$ concentration (lower panel) by enalapril-based treatment. ${ }^{*} \mathrm{p}<0.05$ versus values at entry. B. Changes in plasma BNP concentration (upper panel) and plasma ANP concentration (lower panel) by lisinopril-based treatment. $\mathrm{p}<$ 0.05 versus values at entry.

the cardiac ventricles, but not from the atria. In this study, there was a close, positive correlation between BNP secretory rate from ventricles and ventricular weight in this LVH model before and after antihypertensive therapy.

Although we have no direct evidence, this animal study (45) and our clinical study (44) of BNP and LVH suggest that the regression of LVH by ACEI therapy may cause reduced secretion of BNP from cardiac ventricles. Several explanations have been advanced for the close relation between reductions in plasma BNP concentration and those in $\mathrm{LV}$ mass. First, LV mass and LV synthesis of BNP may have been reduced concomitantly by long-term blockade of angiotensin II in the heart. In fact, angiotensin II is related to BNP secretion from cardiomyocytes as well as the growth of cardiomyocytes (46). An alternative explanation attributes the observed relationship between BNP reduction and $\mathrm{LVH}$ regression to reduced BNP secretion from the cardiac ventricles. This explanation seems at odds with findings that LV systolic func- 


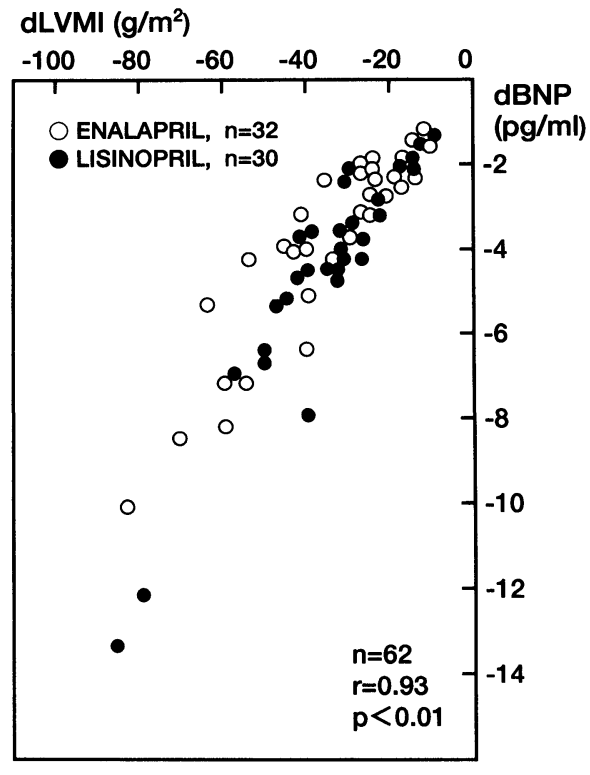

Fig. 8. The relation between changes in plasma brain natriuretic peptide concentration $(d B N P)$ and in left ventricular mass index (dLVMI) in the enalapril group, and both groups during antihypertensive treatment. $\bigcirc=$ enalapril-based treatment group; $\mathbf{O}=$ lisinopril-based treatment group.

tion was not changed by the regression of $\mathrm{LVH}$ and that there was no significant relation between changes in plasma BNP concentration and those in LV systolic function. Therefore, it is likely that changes in the plasma concentration of BNP reflect the magnitude of regression of $\mathrm{LVH}$ in essential hypertension. Thus, plasma BNP concentration may be a useful marker for LVH during antihypertensive therapy in essential hypertensive patients.

LVH increases the hypertensive patient's risk of cardiovascular events, cardiovascular death, and allcause mortality $(47,48)$. The risks are maximized when the patient has concentric hypertrophy, with increases in both relative wall thickness and mass (49). In our recent study (44) concerning BNP and LVH, BNP levels were positively correlated with LV mass index and relative wall thickness, and the reduction in BNP levels by ACEI was closely related to a reduction in $\mathrm{LV}$ mass. In these respects, plasma BNP may be valuable as a prognostic predictor in hypertension. Indeed, plasma BNP levels have an independent significant relationship to mortality in patients with chronic congestive heart failure $(50)$.

\section{BNP As a Novel Form of Therapy for Hypertension}

There are two published reports of the effects of exogenous BNP infused in patients with hypertension. Richards et al. (51) infused human BNP over a period of $2 \mathrm{~h}$ in six male patients with untreated, uncomplicated, mild to moderate essential hypertension. Achieved intrainfusion plasma BNP immunoreactivity was similar to levels previously observed in heart failure or severely complicated hypertension. Plasma cyclic GMP increased, sodium excretion rose 2.5-fold, and plasma aldosterone fell to $50 \%$ of placebo values. Blood pressure and heart rate were unchanged. Their data suggest that in essential hypertension, pathophysiological plasma concentrations of human BNP have significant, acute effects that promote natriuresis and suppress plasma aldosterone. These effects are similar to those of comparable doses of ANP, but the plasma half-life of BNP is considerably longer than that of ANP. Therefore, these two peptides may play separate, complementary roles in fluid volume and blood pressure homeostasis in hypertension.

La Villa et al. (52) infused human BNP in increasing amounts, to raise its plasma concentrations to the pathophysiological range, and evaluated whether and at what plasma level this hormone influences cardiovascular function. BNP induced progressive reductions in left ventricular end-diastolic volume and end-systolic volume, whereas stroke volume did not show any significant change. Cardiac output, arterial pressure, and peripheral vascular resistance did not change significantly. Their data suggest that BNP, at pathophysiological plasma concentrations, influences cardiovascular homeostasis mainly by reducing cardiac preload.

However, more clinical trials studying the effects of BNP treatment in patients with hypertension are necessary to fully evaluate the therapeutic potential of this peptide.

\section{Conclusion}

Plasma BNP concentrations are progressively elevated with increasing severity of hypertension, particularly when LVH is present. This presumably reflects increases in ventricular mass associated with increased synthesis and constitutive secretion of BNP from ventricular tissue. In this respect, plasma BNP may be a marker for hypertensive LVH. Acute administration of BNP induces significant natriuresis and suppresses plasma aldosterone in hypertensive subjects. However, this peptide fails to lower systemic blood pressure significantly in these subjects. Therefore, this possible new form of therapy for hypertension needs further testing in animal and human hypertension.

\section{Acknowledgement}

The authors would like to express their gratitude to Dr. Kenichi Yasunari, Dr. Kohichi Murakawa, Dr. Koji Yokokawa, Dr. Takeshi Horio and Dr. Miwako Ikeda, Division of Hypertension \& Atherosclerosis, First Department of Internal Medicine, Osaka City University Medical School. Thanks are also due to Atsumi Ohnishi and Yuka Inoshita for typing this manuscript. Supported in part by Grant-in-Aid 572-690-646 for Scientific Research from the Ministry of Education, Science, and Culture of Japan and a grant from the Osaka Heart Club. 


\section{References}

1. de Bold AJ, Borenstein HB, Veres At, Sonnenberg $\mathrm{H}$ : A rapid and potent natriuretic response to intravenous injection of atrial myocardial extract in rats. Life Sci 1981, 28: 89-94.

2. Kangawa $\mathbf{K}$, Matsuo $\mathrm{H}$ : Purification and complete amino acid sequence of alpha-human atrial natriuretic polypeptide (alpha-hANP). Biochem Biophys Res Commun 1984; 118: 131-139.

3. Sudoh T, Kangawa K, Minamino N, Matsuo H: A new natriuretic peptide in porcine brain. Nature 1988; 332: 78-81.

4. Mukoyama M, Nakao $\mathrm{K}$, Hosoda $\mathrm{K}$, et al: Brain natriuretic peptide as a novel cardiac hormone in humans. J Clin Invest 1991; 87: 1402-1412.

5. Kambayashi Y, Nakao K, Mukoyama M, et al: Isolation and sequence determination of human brain natriuretic peptide in human atrium. FEBS Lett 1990; 259: 341-345

6. Yandle TG, Richards AM, Gilbert A, et al: Assay of brain natriuretic peptide (BNP) in human plasma: evidence for high molecular weight BNP as a major plasma component in heart failure. $J$ Clin Endocrinol Metab 1993; 76: 832-838.

7. Nakao K, Ogawa Y, Suga S, Imura H: Molecular biology and biochemistry of the natriuretic peptide system, I. Natriuretic peptides. J Hypertens 1992; 10: 907-912.

8. Kohno M, Horio $\mathrm{T}$, Yokokawa $\mathrm{K}$, et al: Brain natriuretic peptide as a cardiac hormone in essential hypertension. Am J Med 1992; 92: 29-34.

9. Sudoh T, Maekawa K, Kojima M, et al: Cloning and sequence analysis of cDNA encoding a precursor for human brain natriuretic peptide. Biochem Biophys Res Commun 1989; 159: 1427-1434.

10. Seilhamer JJ, Arfsten A, Miller JA, et al: Human and canine gene homologs of porcine brain natriuretic peptide. Biochem Biophys Res Commun 1989; 165: $650-658$.

11. Shaw G, Kamen R: A conserved AU sequence from the $3^{\prime}$ untranslated region of GM-CSF mRNA mediates selective mRNA degradation. Cell 1986; 46: 659-667.

12. Kohno M, Horio $\mathrm{T}$, Yokokawa $\mathrm{K}$, et al: Atrial and brain natriuretic peptides: secretion during exercise in patients with essential hypertension and modulation by acute angiotensin-converting enzyme inhibition. Clin Exp Pharmacol Physiol 1992; 19: 193-200.

13. Kohno M, Horio T, Toda I, et al: Cosecretion of atrial and brain natriuretic peptides during supraventricular tachyarrhythmias. Am Heart J 1992; 123: $1382-1384$.

14. Nakamura M, Kawata $Y$, Yoshida $H$, et al: Relationship between plasma atrial and brain natriuretic peptide concentration and haemodynamic parameters during percutaneous transvenous mitral valvulotomy in patients with mitral stenosis. Am Heart J 1992; 124: $1283-1288$.

15. Kohno M, Horio T, Yokokawa $\mathrm{K}$, et al: Pulmonary arterial brain natriuretic peptide concentration and cardiopulmonary haemodynamic during exercise in patients with essential hypertension. Metabolism 1992; 41: 1273-1275.

16. Nakamura S, Naruse $M$, Naruse $K$, et al: Atrial natriuretic peptide and brain natriuretic peptide coexist in the secretory granules of human cardiac myocytes. Am J Hypertens 1991; 4: 909-912.

17. Richards AM, Crozier IG, Espiner EA, Yandle TG,
Nicholls MG: Plasma brain natriuretic peptide and endopeptidase 24.11 inhibition in hypertension. Hypertension 1993; 22: 231-236.

18. Horio T, Shimada K, Kohno M, et al: Serial changes in atrial and brain natriuretic peptides in patients with acute myocardial infarction treated with early coronary angioplasty. Am Heart $J$ 1993; 126: 293-299.

19. Suzuki E, Hirata Y, Kohmoto O, et al: Cellular mechanism for synthesis and secretion of atrial natriuretic peptide and brain natriuretic peptide in cultured rat atrial cells. Circ Res 1992; 71: 1039-1048.

20. Richards AM, Crozier IG, Holmes SJ, et al: Brain natriuretic peptide: natriuretic and endocrine effects in essential hypertension. J Hypertens 1993; 11: 163-170.

21. McGregor A, Richards $M$, Espiner E, Yandle $T$ : Brain natriuretic peptide administered to man: actions and metabolism. J Clin Endocrinol Metab 1990; 70: $1103-1107$.

22. Kita T, Kida O, Yokata N, et al: Effect of brain natriuretic peptide-45, a circulating form of rat brain natriuretic peptide, in spontaneously hypertensive rats. Eur J Pharmacol 1991; 202: 73-79.

23. Gunning $M$, Ballermann BJ, Silva $\mathrm{P}$, Brenner BM, Zeidel ML: Brain natriuretic peptide: interaction with renal ANP system. Am J Physiol 1990; 258: F467-F472.

24. Seymour AA, Blaine EH, Mazack EK, et al: Renal and systemic effects of synthetic atrial natriuretic factor. Life Sci 1985; 36: 33-44.

25. Holmes SJ, Espiner EA, Richards AM, Yandle TG, Frampton C: Renal, endocrine and haemodynamic effects of human brain natriuretic peptide in normal man. J Clin Endocrinol Metab 1993; 76: 91-96.

26. Hashiguchi $\mathrm{T}$, Higuchi $\mathrm{K}$, Ohashi $\mathrm{M}$, et al: Effect of porcine brain natriuretic peptide (pBNP) on human adrenocortical steroidogenesis. Clin Endocrinol (Oxf) 1989; 31: 623-630.

27. Nawata $\mathrm{H}$, Ohashi M, Haji M, et al: Atrial and brain natriuretic peptide in adrenal steroidogenesis. $J$ Steroid Biochem Mol Biol 1991; 40: 367-379.

28. Akabane S, Matsushima Y, Matsuo H, et al: Effects of brain natriuretic peptide on renin secretion in normal and hypertonic saline-infused kidney. Eur $J$ Pharmacol 1991; 198: 143-148.

29. Stephenson SL, Kenny AJ: The hydrolysis of alphahuman atrial natriuretic peptide by pig kidney microvillar membranes is inhibited by endopeptidase-24.11. Biochem J 1987; 243: 183-187.

30. Yoshimura M, Yasue H, Morita E, et al: Haemodynamic, renal and hormonal responses to brain natriuretic peptide in patients with congestive heart failure. Circulation 1991; 84: 1581-1588.

31. Kohno M, Yasunari K, Yokokawa K, et al: Inhibition by atrial and brain natriuretic peptides of endothelin-1 secretion after stimulation with angiotensin II and thrombin of cultured human endothelial cells. J Clin Invest 1991; 87: 1999-2004.

32. Kohno M, Yokokawa K, Horio T, et al: Atrial and brain natriuretic peptides inhibit the endothelin-1 secretory response to angiotensin II in porcine aorta. Circ Res 1992; 70: 241-247.

33. Fukuda Y, Hirata Y, Yoshimi H, et al: Endothelin is a potent secretagogue for atrial natriuretic peptide in cultured rat atrial myocytes. Biochem Biophys Res Commun 1988; 155: 167-172.

34. Winquist RJ, Scott AI, Vlasuk GP: Enhanced release of atrial natriuretic factor by endothelin in atria from hypertensive rats. Hypertension 1989; 14: 111-114.

35. Kohno M, Murakawa K, Horio T, et al: Endothelin 
stimulates release of atrial natriuretic factor in anesthetized rats. Metabolism 1990; 39: 557-559.

36. Hirata Y, Fukuda Y, Iida T: Endothelin-1 stimulates secretion of atrial and brain natriuretic peptides from porcine cardiocytes and increases ANP messenger RNA levels in rat cardiocytes (abstract). $J$ Hypertens 1990; 8 (suppl 3): S92.

37. Kohno M, Horio $\mathrm{T}$, Ikeda $\mathrm{M}$, et al: Angiotensin II stimulates endothelin-1 secretion in cultured rat mesangial cells. Kidney Int 1991; 42: 860-866.

38. Kohno M, Horio $\mathrm{T}$, Ikeda $\mathrm{M}$, et al: Natriuretic peptides inhibit mesangial cell production of endothelin induced by arginine vasopressin. Am J Physiol 1993; 264: F678-F683.

39. Kohno M, Ikeda M, Johchi M, et al: Interaction of PDGF and natriuretic peptides on mesangial cell proliferation and endothelin secretion. Am J Physiol 1993; 265: E673-E679.

40. Ermiro R, Avanzino GL, Ruggeri P, Bergaglio M, Calaresu FR: Cardiovascular effects of microinjection of ANF and brain natriuretic peptide into ventrolateral medulla. Am J Physiol 1990; 259: R32-R37.

41. Makiko $S$, Hashimoto $\mathrm{K}$, Hirasawa $\mathrm{R}$, Hattori $\mathrm{T}$, Ota Z: Central interaction between endothelin and brain natriuretic peptide on vasopressin secretion. $J$ Hypertens 1992; 10: 25-28.

42. Mukoyama M, Nakao K, Saito Y, Ogawa Y, Hosoda $\mathrm{K}$, et al: Human brain natriuretic peptide, a novel cardiac hormone. Lancet 1990; 335: 801-802.

43. Kohno $M$, Horio $T$, Yoshiyama $M$, Takeda $T$ : Accelerated secretion of brain natriuretic peptide from the hypertrophied ventricles in experimental malignant hypertension. Hypertension 1992; 19: 206-211.

44. Kohno M, Horio T, Yokokawa $\mathrm{K}$, et al: Brain natri- uretic peptide as a marker for hypertensive left ventricular hypertrophy: changes during 1-year antihypertensive therapy with angiotensin-converting enzyme inhibitor. Am J Med 1995; 98: 257-265.

45. Kohno M, Fukui T, Horio T, et al: Cardiac hypertrophy and brain natriuretic peptide in experimental hypertension. Am J Physiol 1994, 266: R451-R457.

46. Horio $\mathrm{T}$, Kohno $\mathrm{M}$, Takeda $\mathrm{T}$ : Effect of arginine vasopressin, angiotensin II and endothelin-1 on the release of brain natriuretic peptide in vivo and in vitro. Clin Exp Pharmacol Physiol 1992; 19: 575-582.

47. MacMahon S, Collins G, Rautaharju P, et al: Electrocardiographic left ventricular hypertrophy and effects of antihypertensive drug therapy in hypertensive participants in the Multiple Risk Factor Intervension Trial. Am J Cardiol 1989; 63: 202-210.

48. Multiple Risk Factors Intervention Trial Research Group: Multiple risk factor intervention trial risk factor changes and mortality results. JAMA 1982; 248: 1465-1477.

49. Koren MJ, Devereux RB, Casale PN, et al: Relaton of left ventricular mass and geometry to morbidity and mortality in uncomplicated essential hypertension. Ann Intern Med 1991; 114: 345-352.

50. Tsutamoto T, Maeda Y, Wada A, et al: Plasma brain natriuretic peptide concentration as a prognostic predictor in patients with chronic congestive heart failure. Circulation 1993; 88 (4): 126. Abstract.

51. Richards AM, Crozier IG, Holmes SJ, et al: Brain natriuretic peptide: natriuretic and endocrine effects in essential hypertension. $J$ Hypertens 1993; 11: 163-170.

52. Villa GL, Bisi G, Lazzeri C, et al: Cardiovascular effects of brain natriuretic peptide in essential hypertension. Hypertension 1992; 25: 1053-1057. 